\title{
Guided inquiry e Construtivismo: novos métodos de aprendizagem e a biblioteca escolar ${ }^{1}$
}

\author{
Guided inquiry and Constructivism: new methods of learning and the school library
}

$\begin{array}{r}\text { Maria L. Amorim Antunes } \\ \text { Mestra em Ciência da Informação pela Escola de Ciência da Informação da Universidade Federal de Minas } \\ \text { Gerais - UFMG. } \\ \text { E-mail: mariaamorimm@gmail.com }\end{array}$

Adriana Bogliolo Sirihal Duarte

Doutora em Ciência da Informação pela Escola de Ciência da Informação da Universidade Federal de Minas Gerais - UFMG.

Professora associada da Escola de Ciência da Informação da Universidade Federal de Minas Gerais - UFMG.

E-mail: bogliolo@eci.ufmg.br

\section{Resumo}

Em uma realidade cada vez mais caracterizada pela presença da tecnologia, muito se tem refletido sobre os rumos da educação e da biblioteca escolar. Como existe uma estreita vinculação da biblioteca à instituição em que está inserida e hoje a realidade das escolas e de suas bibliotecas opera especificamente na lógica dos nativos digitais, este artigo se propõe a discorrer sobre novos parâmetros de educação, ensino e pesquisa de um contexto educativo pautado pela Internet, analisando-os dentro da lógica construtivista. Para tanto, descreve-se as peculiaridades de uma instituição privada de ensino de Belo Horizonte (MG), investigada através de métodos etnometodológicos com técnicas de observação e entrevistas, e confronta-se o comportamento informacional de seus alunos com as contribuições de Carol Kuhlthau. Reflete-se sobre a viabilidade de novas propostas de prática bibliotecária e métodos de aprendizagem. Conclui-se que em tempos em que se fala do caráter pedagógico da biblioteca e do bibliotecário-educador as pesquisas se mostram dirigidas cada vez mais para modelos de competência informacional.

Palavras-chave: Construtivismo. Pesquisa escolar. Guided inquiry. Biblioteca escolar.

\begin{abstract}
In a reality increasingly characterized by technology, much has been reflected on the future of education and the school library. As there is a close link from the library to the institution in which it operates and since today the reality of schools and their libraries operates specifically in the digital natives logic, this article aims to discuss new educational, teaching and research parameters in an educational context guided by the Internet, within the constructivist logic. To do so, it describes the peculiarities of a private school located at Belo Horizonte (MG), investigated through ethnomethodological methods with interviews and observation techniques, and it confronts the information behavior of their students with some theoretical contributions from Carol Kuhlthau. After all, it reflects on the viability of new proposals for librarian practice and learning methods. We conclude that in times when it comes to the pedagogical nature of the library and librarian-teacher, the research is increasingly aimed to show information literacy models.
\end{abstract}

Keywords: Constructivism. Scholar research. Guided inquiry. School library.

\footnotetext{
${ }^{1}$ Artigo produzido a partir dos dados coletados para a dissertação Comportamento Informacional em tempos de Google, desenvolvida no Programa de Pós-Graduação em Ciência da Informação - PPGCI, UFMG, defendida em dez. 2015.

ANTUNES, M. L. A. Comportamento informacional em tempos de Google. 206 f. 2005. Dissertação (Mestrado em Ciência da Informação) - Universidade Federal de Minas Gerais, Escola de Ciência da Informação, 2015
}

Bibl. Esc. em R., Ribeirão Preto, v. 5, n. 1, p. 19-35, 2016.

DOI: 10.11606/issn.2238-5894.berev.2016.112156 


\section{Introdução}

Diante de uma realidade cada vez mais caracterizada pela presença maciça da tecnologia, muito se tem refletido sobre os rumos da educação, da escola e da biblioteca escolar. São diversos os autores - Sibilia, 2012; Oliveira; Schwartzman, 2002; Miller; Pellen, 2005; Lanzi; Vidotti; Ferneda, 2013; Williams, 2007, dentre outros - que indicam um consenso de que na "escola da era da informação" a tecnologia estará cada vez mais integrada aos propósitos da aprendizagem. Como sugere Oliveira (2013) existe uma estreita vinculação da biblioteca à instituição em que está inserida: o desempenho da escola tem um impacto direto na atuação dos alunos e, por conseguinte, na concepção que estes têm da biblioteca. Esta, por sua vez, tem um impacto direto no aprendizado, em uma relação muito estreita. Como hoje a realidade das escolas e de suas bibliotecas opera especificamente na lógica dos nativos digitais - indivíduos que nasceram e cresceram em meio à tecnologia digital (PRENSKY, 2001; PALFREY, GASSER, 2008; TAPSCOTT, 2009) - este artigo particulariza um modelo de pesquisa e aprendizado em um contexto educativo pautado pela Internet, passível de ser integrado à agenda de trabalho dos bibliotecários.

Araújo, Braga e Vieira (2010) sugerem que nas últimas décadas o Brasil vem observando um grande crescimento na pesquisa em Ciência da Informação. Segundo eles, uma das formas de se favorecer este incremento é identificar as maiores influências para a área, tanto em termos de pesquisadores quanto da contribuição dos mesmos. As análises realizadas por estes autores destacaram especificamente a conceituada pesquisadora norte-americana Carol C. Kuhlthau, uma das precursoras na área de busca da informação. Seu modelo sobre o processo de busca de informação é referência em grande parte dos trabalhos que retratam estudos de usuários ou que discutem o letramento informacional.

Nesta abordagem, confrontam-se as contribuições de Kuhlthau, especificamente o modelo guided inquiry, com dados de uma pesquisa qualitativa coletados em uma instituição privada de ensino de Belo Horizonte. Analisando as peculiaridades e a atividade de pesquisa dos jovens alunos desta escola reflete-se sobre uma nova proposta de prática bibliotecária e métodos de aprendizagem. 
Maria L. Amorim Antunes e Adriana Bogliolo Sirihal Duarte

\section{Inquiry Learning e Guided Inquiry}

Segundo Kuhlthau (1999) a educação, em uma sociedade democrática, incide sobre três pilares fundamentais: preparar o aluno para o mercado de trabalho, para a cidadania e para o mundo. Ainda que um considerável tempo tenha decorrido depois desta afirmativa, pode-se dizer que pensar a escola da sociedade da informação é um desafio contemporâneo e envolve discussões complexas sobre como a escola está se modificando, sobre o que representa ser alfabetizado informacionalmente nesta sociedade e qual o papel da biblioteca escolar no processo de aprendizagem.

Com estas preocupações, surge a premissa de conceber um método de aprendizagem para o longo da vida, capaz de envolver o estudante em todos os estágios do aprendizado desde o planejamento até o produto final. Esta conjuntura requer um currículo conectado ao mundo dos estudantes, a colaboração entre alunos e professores, a integração entre conteúdos de áreas diferentes, o conceito de informação transferível e o uso de múltiplas fontes; gerando uma comunidade de aprendizes trabalhando conjuntamente (Kuhlthau, 2004, p. 6).

O Inquiry Learning, doutrina que abrange o Guided Inquiry, surge neste contexto. Pode ser descrito como um "modo de pensar, aprender e ensinar que muda a cultura da escola no sentido de instituir uma comunidade investigativa colaborativa" (KUHLTHAU; MANIOTES, CASPARI, 2012, p. xiii). Estes autores acreditam que o processo de investigação guiada incentiva os alunos a interagir com a informação, com foco na aprendizagem, ou seja; "aprender a aprender" ao invés da simples memorização dos fatos. O Inquiry Learning é descrito por eles como uma estrutura de formação de equipes e currículos interdisciplinares flexíveis, capazes de transformar a educação em um sistema mais apropriado para o século 21 . Isto exige a criação e manutenção de uma cultura educacional de colaboração de toda a comunidade escolar: envolve os alunos cooperando entre si, uma cultura de colaboração entre os professores, a relação de ambos (professores e alunos), entre todos os níveis da administração da escola, dos pais e professores e também diretores e membros de conselhos. Prevê, ainda, a construção de uma fundação de estratégias de aprendizagem e habilidades de pesquisa que irão beneficiar os alunos em todas as etapas da educação, bem como em suas respectivas carreiras.

O Guided Inquiry, ou a proposta de investigação orientada, apresenta-se a partir desta ideia inicial: da busca dirigida objetivar uma preparação do aluno para o aprendizado no decorrer da vida, ao invés de focar em uma tarefa específica. Trata-se de um processo 
constituído de duas partes: do modelo de Kuhlthau do processo de busca de informações (Information Search Process - ISP) e do estudo de um "terceiro espaço" ou "terceira dimensão", teoria da informação de Maniotes, que idealiza uma interseção dinâmica entre os conteúdos do currículo escolar e dos conhecimentos do aluno, criando espaços de aprendizagem que envolvem o educando fora de sala de aula. Desta forma os estudantes usam o seu conhecimento de mundo como recurso no conteúdo do currículo e em novos entendimentos em suas vidas (KUHLTHAU; COLE, 2012).

O diferencial deste processo reside no fato do mesmo ir além da mera capacidade do sujeito em identificar uma tarefa, coletar informação e cumprir a incumbência. Abrange um complexo processo de pensamento, aprendizagem e inovação no ensino que envolve os professores e a biblioteca. Segundo Kuhlthau (2004), os professores e bibliotecários capazes de reconhecer o momento crítico em que a orientação e instruções são mais essenciais, podem designar intervenções que capacitem os estudantes a pegar ideias, registrar nova informação e adquirir conhecimento de forma consciente no processo de aprendizado. Na sociedade da informação estas asserções são estendidas para, além de ensinar o educando a utilizar os dispositivos, fazê-lo usufruir dos mesmos de forma produtiva na criação do conhecimento. É o que acredita Kuhlthau (2010).

Para este método identificam-se oito fases e descrevem-se seis ferramentas que são essenciais para sua implementação. As etapas iniciar (open), mergulhar (immerse), explorar (explore), identificar (identify), reunir (gather), criar (create), compartilhar (share) e avaliar (evaluate), bem como os instrumentos de empregabilidade: colaboração (collaborate), conversa (converse), composição (compose), decisão/escolha (choose), esboço (chart) e continuação (continue), são analisadas adiante, no dia a dia e nas tarefas dos alunos.

Fialho (2013) atesta que o modelo ISP de Kuhlthau foi desenvolvido sob a visão construtivista do aprendizado. De acordo com ela, o construtivismo aborda o aprendizado como um processo dinâmico, no qual o sujeito é agente ativo do próprio conhecimento. Todos os aspectos da experiência interagem orientados por sentimentos, que por sua vez, dialogam com pensamentos e ações. Neste enfoque, um ambiente construtivista de aprendizagem propicia para que o indivíduo crie sentido através de informação contextualizada, aquela vinculada às experiências do sujeito, por sua vez possuidor de conhecimentos prévios em relação a essa. Com o interesse em incentivar as habilidades do educando de avaliar e utilizar as informações 
Maria L. Amorim Antunes e Adriana Bogliolo Sirihal Duarte

para identificar problemas, apresentar soluções e adquirir crescimento pessoal, destaca-se uma análise feita em uma instituição que trabalha estes ideais: o embasamento construtivista.

Detalhando melhor os processos de busca e sentimentos associados a cada etapa da teoria de Kuhlthau observa-se uma correspondência entre as fases do modelo ISP e as fases do processo guided inquiry, bem como sua associação às ferramentas de implementação.

\section{Quadro 1: Fases dos modelos ISP e Guided Inquiry e ferramentas de implementação.}

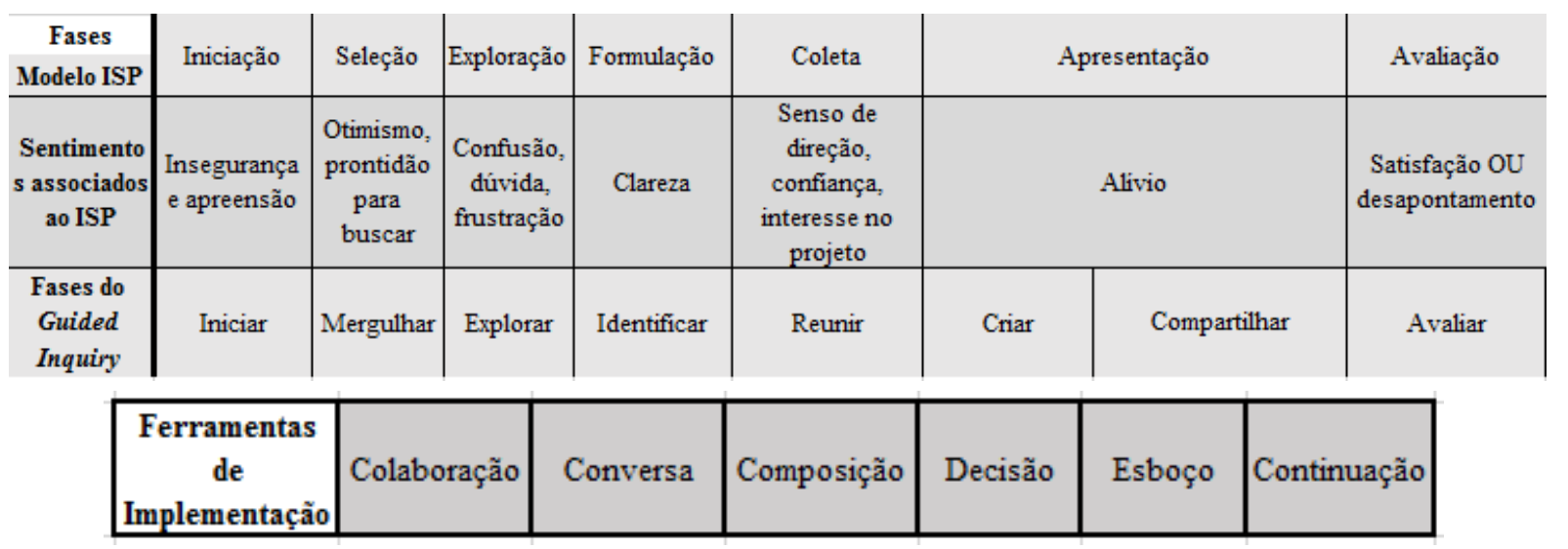

Fonte: Elaborado pelas autoras.

No modelo ISP as necessidades cognitivas relacionam-se com as reações emocionais; o processo de busca da informação é permeado por elas. O nível de incerteza varia durante o processo de busca da informação (princípio de incerteza) e pode ser observado em seis estágios, divididos em três campos de experiência: emocional, cognitivo e físico.

O estágio de iniciação acontece quando o estudante reconhece que necessita de informação e assume sentimentos de incerteza e apreensão. A seleção trata da delimitação do campo ou tema e de identificar e selecionar um tópico geral de pesquisa. Destacam-se nesta fase algumas percepções como interesse pessoal, quantidade de informação disponível, esforço e tempo que serão despendidos. A exploração do tema, dos documentos e fontes constitui a terceira etapa. Envolve buscar informação sobre o tópico geral escolhido para ampliar a compreensão pessoal e estabelecer um foco mais nítido sobre o mesmo. A formulação, quarto estágio do modelo ISP, é considerada o momento crucial do processo. O sentimento de incerteza diminui e o pesquisador estabelece uma linha de ação; descarta as informações generalizadas e identifica e seleciona ideias para formar uma perspectiva sobre o tópico. A coleta retrata a atividade de centrar os pensamentos para definir e dar suporte ao foco, através da seleção de informação pertinente e anotações detalhadas do que tem relação específica com o foco. No 
estágio de apresentação dá-se o 'fim' da busca e a 'solução' do problema. É comum o sentimento de alívio associado à satisfação ou desapontamento dependendo do sucesso da pesquisa empreendida. Posteriormente à conclusão do processo de pesquisa ocorre a avaliação; momento de reflexão no qual os estudantes analisam o processo e o resultado em si: o que os auxiliou, que dificuldades tiveram, etc. Fialho (2013, p. 19) rememora existir uma discussão se esta seria uma fase separada ou integrante do sexto estágio, porém declara que Kuhlthau (2004) expõe alguns aspectos da avaliação incorporados ao estágio de apresentação.

O design do processo de investigação orientada se inicia com a abertura, para atrair a atenção dos estudantes, estimular a atividade reflexiva dos mesmos e então ajudá-los a fazer conexões com o mundo fora da escola. Em sequência, a imersão, designada para construir conhecimentos prévios suficientes para gerar ideias interessantes de investigação. A seguir temse a exploração dessas ideias para um importante e autêntico engajamento da questão de investigação. Há uma pausa para identificar, clarear e articular a questão de pesquisa antes de passar para o recolhimento da informação. Após este recolhimento seguem a criação e o compartilhamento do que os estudantes aprenderam e então a avaliação para refletir sobre os conteúdos e processos e estimar a aquisição do aprendizado ou conhecimento. A pesquisa orientada é designada para encorajar a construção de um conhecimento colaborativo de reflexão e avaliação do aprendizado, que segundo os autores ocorre através deste processo (KUHLTHAU; MANIOTES; CASPARI, 2012).

Os estudos de Kuhlthau identificaram nos estágios do ISP um número de estratégias que podem ser trabalhadas pelo professor e bibliotecário para serem adotadas pelos estudantes. A primeira delas é a colaboração. Como o questionamento ou investigação ocorrem em um contexto social, estimular a colaboração habilita os estudantes a tentar novas ideias e escutar outras perspectivas em várias fases do processo investigação. O modelo ISP mostrou que os estudantes padecem quando tratam um tópico de pesquisa de forma isolada e competitiva. A segunda ferramenta, a conversa, ajuda os alunos articular o raciocínio e identificar lacunas ou inconsistências no próprio pensamento. É uma intervenção estratégica para ajudar os estudantes trabalhar através dos estágios da busca orientada, pois à medida em que conversam entre si e com os educadores, elaboram as ideias. A composição é a terceira tática, que busca promover o pensamento através do processo de busca orientada. A composição capacita a construção de novas ideias e formas de aprendizado. Escrever e manter diários e cadernos de pesquisa são pontos importantes para adotar ou nutrir linhas de pensamento. A escolha ou seleção, quarto instrumental, é o que habilita o sujeito a aprender como assumir o controle do próprio processo 
Maria L. Amorim Antunes e Adriana Bogliolo Sirihal Duarte

de busca por informação. O time ou grupo de pesquisa orientada designa algumas intervenções que ajudam os estudantes a aprender que investigar requer fazer escolhas; quais perguntas fazer, que tópico escolher, que fonte consultar, que abordagem adotar e que metodologia empregar. Em quinto, dá-se o esboço. Realizar esboços ou gráficos permite aos alunos apresentar uma grande quantidade de informação de modo compacto. Trabalha a visualização como um importante modo de construção que auxilia o processo de aprendizado. Por fim, a continuação envolve despertar e manter a atenção para continuar com o projeto até a completude. Requer persistência e perseverança. Os estudos do modelo ISP mostram que a melhor motivação para continuar é dirigida por interesses pessoais. Uma perspectiva focada que se desenvolve ao longo do processo de busca orientada também encoraja a continuidade.

Diante do exposto, considera-se que tanto o modelo ISP quanto o processo de pesquisa orientada e as ferramentas de implementação mostram-se artifícios valiosos para reforçar a variedade de competências e conhecimentos que os estudantes podem adquirir. Dentre estas competências destacam-se especialmente: o aprender a aprender, o conteúdo curricular, o letramento informacional, a literacy competence (ler, escrever, falar, ouvir, assistir e apresentar) e as habilidades sociais (KUHLTHAU, 2010, p. 22-23). Ressalta-se que, não obstante criar condições para o desenvolvimento de tais competências através destas ferramentas seja distinto de garantir efetivamente esse desenvolvimento, acredita-se que investir no desdobramento destes estudos mostre um resultado bastante promissor para a educação.

\section{Método: a Escola pesquisada}

A coleta de dados, embasada na etnometodologia, fez uso da observação simples durante o período de aproximadamente um ano letivo, acompanhada de entrevistas semiestruturadas em profundidade, em diferentes momentos ao longo desse período, com um grupo dos alunos observados.

A escola pesquisada é uma instituição laica e particular da cidade de Belo Horizonte, que atua desde a Educação Infantil até o Ensino Médio, sendo este o foco de análise. Tem uma proposta pedagógica diferenciada e considerada inovadora no Brasil. Desde o início de 2014, a escola vem implementando mudanças nos padrões tradicionais de ensino, o que envolveu a adoção de um currículo aberto e reformas físicas no ambiente da escola. As grandes peculiaridades deste novo modelo, centrado em bases construtivistas, residem no destaque à 
Guided inquiry e Construtivismo: novos métodos de aprendizagem e a biblioteca escolar

autonomia do sujeito, no emprego da pesquisa escolar como ferramenta essencial de efetivação e consolidação do aprendizado e na colaboração entre os estudantes (nas mesas).

A pesquisa escolar, feita da forma convencional (solicitada pelo professor e trabalhada em casa), não corresponde à realidade da escola em estudo. Ao contrário, a pesquisa parte do dia a dia das aulas e é constituinte do método de ensino, sendo incorporada a ele para despertar o espírito investigativo dos alunos, o interesse dos mesmos pelo conteúdo e habilidades em se relacionar com a informação. Como se evidencia no trecho do Plano Pedagógico abaixo, os meios e os fins da escola em questão se aproximam muito dos princípios de Kuhlthau, tanto no que se refere ao emprego da pesquisa, quanto no interesse em preparar o sujeito para a vida:

Se desejamos formar jovens pesquisadores, produtores de conhecimento, capazes de contribuir para a transformação do mundo, é essencial que desenvolvam o espírito investigativo, aprendendo a lidar com a pesquisa. Por isso, desde a Educação Infantil até o Ensino Médio, a pesquisa constitui a estratégia prioritária de produção de conhecimento (Projeto Pedagógico da Escola Investigada; revisado e atualizado para o ano letivo de 2015; grifo nosso) ${ }^{2}$.

$\mathrm{Na}$ escola não existem paredes, não existem salas de aula nem apresentações expositivas usuais por parte dos docentes (salvo diante de solicitação expressa de alunos quando necessitam tirar alguma dúvida pontual; apenas nesses casos, excepcionalmente, trabalha-se em salas menores específicas para este fim e com um grupo reduzido de alunos - de um a cinco, em média). Com exceção das partes diversificadas, as 'aulas' (talvez a denominação 'encontros' fosse mais apropriada) acontecem em salões, onde ficam dispostas estantes com livros didáticos, paradidáticos e literários, computadores e mesas com 4 ou 6 cadeiras - nas quais os alunos se organizam em grupos de trabalho e recebem roteiros temáticos, método pelo qual acontece o início do processo de aprendizagem.

O método de avaliação também é personalizado. Existem módulos nos quais se divide a totalidade do conteúdo programático. Como são os alunos que administram o tempo e o prazo para terminar os roteiros, quando se sentem prontos solicitam e marcam as avaliações com o professor de cada área do conhecimento.

Os estudantes começam a cumprir suas atividades separando e integrando o que é individual e o coletivo. Se sentem dificuldades, pedem apoio aos colegas (de sua própria mesa ou de outras) ou ao professor, que então dá explicações para grupos ou alunos específicos. Normalmente ficam 3 ou 4 professores (relativos à área do conhecimento) presentes no salão à

\footnotetext{
${ }^{2}$ Parte não integrante das referências bibliográficas para preservar a identidade da instituição.
} 
disposição dos alunos. Estes ficam percorrendo as mesas e acompanhando os estudantes. Não se observou o apoio ou intervenção do bibliotecário nestas atividades - uma crítica e sugestão a ser feita.

Foram entrevistados quatro alunos, com idades entre 14-17 anos, duas do sexo feminino e dois do masculino. Estes jovens cursam o terceiro ciclo, que equivale ao Ensino Médio (de acordo com o Plano Pedagógico, “o Ensino Médio constitui um ciclo em si, que corresponde à juventude"). O perfil socioeconômico dos mesmos permite que sejam classificados na categoria classe "média-alta". Todos declararam ter condições de manter acervos particulares de livros e fácil acesso a demais materiais bibliográficos. Quanto às tecnologias, não são excluídos digitalmente: todos têm computadores, todos têm acesso regular à Internet, alguns levam tablets e computadores próprios, outros usam os da Escola na ocasião das aulas. Os estudantes convivem com diversas tipologias de material e os têm disponíveis ao alcance das mãos. A utilização fica a critério deles e o que varia usualmente é a recomendação do professor.

\section{Resultados e Discussão}

Como mencionou-se previamente, a escola em questão tem como condição especial o compromisso em tornar o aluno autor do próprio aprendizado. A atividade de pesquisa é administrada nas práticas cotidianas, uma vez que configura o núcleo do instrumento educativo da instituição. Trabalha portanto, a capacidade do educando de, ao se confrontar com algum problema, tema ou matéria de estudo, saber pesquisar, elaborar respostas e construir o próprio conhecimento. Partindo desta premissa, verificou-se a necessidade de conhecer o processo operacional dos alunos; o que pensam da escola e como trabalham a metodologia adotada. Intencionou-se verificar como os entrevistados começam as buscas por informação e quais os sentimentos associados à necessidade de informação. Foi investigada a opinião dos alunos sobre o método de ensino da escola e como se posicionam diante do próprio aprendizado, bem como os sentimentos envolvidos no processo de aprendizado, o ritmo aplicado no cumprimento do conteúdo e o afinco com a tarefa. Também fizeram parte dos critérios de observação e análise o procedimento de trabalho dos alunos; os critérios que adotam para iniciar os roteiros, buscar informação e elaborar a argumentação das questões. Especifica-se o conteúdo observado a seguir:

1. Como avaliam o método de ensino da escola

2. Como se posicionam ante o próprio aprendizado; 
3. O sentimento dos mesmos ao receberem o roteiro;

4. O ritmo aplicado no cumprimento do conteúdo;

5. Se optam ou não por manter registros do aprendizado;

6. Os critérios que adotam para iniciar os trabalhos;

7. Se têm necessidade da ajuda de terceiros;

8. Se têm a necessidade e valorizam o feedback do professor;

9. Se mostram inclinação ao suporte impresso ou digital (tanto na organização das ideias, registro e apresentação do material, quanto no momento da consulta);

10. Como fazem a escolha das fontes, e

11. Como trabalham as citações e percebem a questão da cópia da Internet.

Confrontando a descrição dos alunos sobre seus processos de busca e relação com a informação observou-se que:

Normalmente, há a distribuição dos roteiros, que contemplam séries do conteúdo da matéria. O roteiro usualmente contém um texto base que introduz o assunto e depois uma série de exercícios e questionamentos em tópicos que os alunos têm de compreender, argumentar e resolver. A própria instituição e estruturação dos roteiros são diferentes, bem como a postura de cada professor. Neste momento é perceptível as duas primeiras fases do modelo ISP: a iniciação, que acontece quando o estudante lê o roteiro e se depara com a necessidade de informação; e a seleção, com a delimitação do campo de pesquisa e a atividade de traçar as primeiras reações baseadas no interesse pessoal, como prevê o modelo. Nenhum dos alunos declarou realizar os roteiros no momento e ordem em que os recebe, fazendo primeiramente os que mais os agradam ou os considerados mais fáceis. $\mathrm{O}$ fato da falta de afinidade com o assunto atravancar o rendimento foi o único grande desafio apontado pelos alunos no que tange a didática construtivista. Quando o tópico de estudo não os agrada, eles assumem ter sentimentos ruins, de repúdio, reclamação e falta de paciência. Reações comuns foram a queixa com a procrastinação e a grande dificuldade em manter a autodisciplina nesses casos. Também há relação com o framework da pesquisa orientada: a abertura pode ser adotada como estratégia pelos professores na formulação dos roteiros, para atrair a atenção dos estudantes e estimular a reflexão dos mesmos, assim ajudando a fazer conexões com o mundo e demais dimensões designadas para construir conhecimento. 
De forma geral é sugerido ao aluno fazer a leitura prévia do resumo que vem contido no roteiro, que apresenta o assunto e indica as exigências do conteúdo. É costume virem inclusas algumas orientações gerais no próprio roteiro, mas cada estudante decide como realizar o trabalho. Quando não há nenhuma orientação específica, alguns alunos pedem instruções para então decidir "o que fazer depois", mas, habitualmente, os participantes disseram que o primeiro passo é sempre ler o texto base para entender mais o assunto e depois elaborar as estratégias que vão empregar para iniciar a pesquisa. Este é o instante em que se nota a fase 3, a exploração do tema, dos documentos e das fontes, ao passo que a pesquisa orientada também promove a exploração das ideias para originar o engajamento da questão de investigação do aluno.

Como explicado, os alunos recebem o plano contendo uma escrita introdutória e as considerações e questionamentos exigidos, considerados indispensáveis para o entendimento completo do tópico que se apresenta. Este roteiro, muitas vezes, além das indicações do que é esperado dos alunos, vem com sugestão de fontes. Contudo, como é objetivo central da escola formar "jovens pesquisadores, produtores de conhecimento" (Plano Pedagógico), trabalhar o espírito investigativo do aluno é estratégia prioritária. Sendo assim existe a proposta de materiais pelos professores, muito embora eles também tenham que deixar os alunos mais livres e autônomos; apenas conduzindo o raciocínio dos mesmos. Como demonstraram os alunos, a indicação de fontes difere em cada caso, em cada disciplina e em cada roteiro.

A busca mais profunda por informação (envolvendo busca, análise e seleção da fonte antes da extração da informação) tem início principalmente quando não há indicação expressa do material a ser utilizado. É a partir daqui que se desdobra a análise sobre as fontes consultadas pelos estudantes. Como expressa um entrevistado, "quando ele [professor/roteiro] não fala nada a gente busca informação". Nesta atividade, a busca de informação empreendida pelos alunos para começarem a cumprir o roteiro corresponde à formulação e coleta do modelo de Kuhlthau. $\mathrm{Na}$ formulação os alunos estabelecem a linha de ação e começam a identificar e selecionar ideias para formar suas perspectivas sobre o tópico. A partir daí começam a seleção de fontes, em que se observa a interação com sistemas e serviços de informação, como descreve o modelo. Esta fase na pesquisa orientada é o momento no qual se sugere aos professores e bibliotecários auxiliar a identificação, elucidação e articulação da questão de pesquisa, que precederá a reunião de material, quando novamente as orientações do professor e bibliotecário se fazem importantes. 
Guided inquiry e Construtivismo: novos métodos de aprendizagem e a biblioteca escolar

No(s) último(s) estágio(s) do modelo de Kuhlthau tem-se a apresentação com o fim da busca e solução do problema e também a avaliação, momento em que os estudantes refletem sobre o processo que empreenderam e o resultado que atingiram. No modelo da pesquisa orientada, a fase de apresentação corresponde à criação e compartilhamento; representa a materialidade do que foi produzido pelo aluno, o que é sugerido compartilhar. Também existe avaliação neste modelo de busca orientada. Ao final dos roteiros, os alunos por vezes avaliam o processo de aprendizado de forma mecânica e automática: de um lado se sentem satisfeitos em avançar no conteúdo, de outro, demonstram certo desânimo ou indiferença, pois 'quando acabam um, recebem outro'. Contudo, foi possível perceber que é a afinidade com a disciplina e o sentimento atrelado ao recebimento do roteiro que determinam o ritmo de trabalho. Muitos deles declararam sentimentos de alívio e satisfação se sentem que fizeram um bom trabalho. Sobressaiu a importância que os mesmos conferem à liberdade de ação. Através da autonomia conferida a eles, os alunos trabalham a responsabilidade e a consciência. Desta forma, sentem que assumem uma postura ativa e se percebem parte integrante do processo de construção do conhecimento.

Com relação às ferramentas descritas no método da pesquisa orientada, foi possível observar que no dia a dia da escola, algumas delas fazem parte do cotidiano de alunos e professores sendo, portanto, parte complementar que sustenta a metodologia de ensino da escola, ressaltando-se o construtivismo. Duas ferramentas que se destacam de forma bem nítida e paralela são a colaboração e a conversa. Os estudos de Kuhlthau descrevem que a investigação ocorre em um contexto social. Sendo assim a colaboração é o que habilita os estudantes a ouvir novas ideias, trabalhar outras perspectivas enquanto a conversa os ajuda articular o raciocínio e identificar incoerências no próprio pensamento. Tal como explicado, as aulas acontecem em salões, onde são dispostas as mesas com 6 cadeiras (grande maioria), em que os alunos se organizam em grupos de trabalho e recebem roteiros temáticos e dão início ao processo de pesquisa e aprendizagem. As mesas são compostas seguindo critérios bem específicos. Procura-se manter em todas as mesas a heterogeneidade: de idade, sexo e afinidade com as disciplinas. O objetivo é equilibrar o grau de conhecimento entre alunos, pois além de aprender eles são estimulados a compartilhar e colaborar com o aprendizado dos demais colegas. Quando perguntou-se com que frequência costumam pedir ajuda, um dos entrevistados declarou ser algo mais raro: "vou mais por mim"; outro confessou se considerar bastante individualista preferindo também fazer o roteiro com as próprias ferramentas. Ainda assim ambos não negaram ajudar aos colegas quando lhes pedem: "normalmente eu não peço ajuda 
para fazer um roteiro; normalmente eu ajudo muito". Os dois demais revelaram pedir ajuda com mais frequência, um deles mais na área de humanas, que é a que tem mais dificuldade.

Outros dois fatores descrito como ferramenta no modelo de pesquisa orientada e ressaltado na escola pesquisada foram a composição e o esboço. Quanto à manutenção de registros, apenas um aluno não declarou explicitamente o costume de organizar as ideias; sintetizando e transcrevendo o conteúdo para fixar o aprendizado e tomando notas das etapas já cumpridas. Na fala dele: “eu faço algumas anotações, dou algumas grifadas”, mas não sistematicamente. Os demais alunos relataram a necessidade de escrever e manter arquivos como forma de fixar o que estão aprendendo e perceber que estão avançando na matéria: um participante declara preferir organizar tudo cronologicamente escrevendo em fichários e outro confessa: “eu gosto de colocar qual é o roteiro, tema, data que eu 'tô' fazendo, tudo, a matéria, coisas assim... Eu vou fazendo o meu próprio resumo do resumo”. Destaca-se contudo, que esta atividade de tomar anotações é prerrogativa do aluno e não é exigência dos professores.

O quarto instrumental do modelo guided inquiry, a decisão, habilita e estimula o sujeito a aprender como assumir o controle do próprio processo de busca por informação e aprendizado e é, talvez, a ferramenta que mais retrata o núcleo essencial da escola. O interesse da instituição é ajudar os alunos a manter o controle do caminho de aprendizagem e de cada escolha, mudança de direção ou momento importante ao longo de sua trajetória. Além de aprender saberes a escola zela para que seus estudantes aprendam valores. As falas dos participantes mostraram interseções comuns, com algumas variações. No geral eles consideram que o método de ensino da escola é somatório do tradicional com elementos originais; o que fortalece a qualidade. Segundo um aluno: "se existem pessoas diferentes, precisa ter métodos de ensino diferentes". A relação dos benefícios diante dos inconvenientes mostrou que o lado positivo se sobressaiu. Ao serem perguntados sobre o que mais valorizavam dentre as possibilidades oferecidas pela metodologia empregada, os aspectos mais elencados pelos participantes foram a independência, a liberdade e a possibilidade de escolha. Isto também se relaciona com a continuação, que tem por objetivo despertar e manter a atenção para que os estudantes continuem com seus projetos até a completude, uma das premissas do Projeto Político Pedagógico da escola investigada.

Retomando, acredita-se que o referencial proporcionado pela doutrina Inquiry Learning oferece meios de otimizar o aprendizado e inspirar a ação de professores e bibliotecários, o que se comprovou no aparecimento de características comuns a todos: assim como as peculiaridades da metodologia de trabalho (ritmo de execução, feedback dos professores e a necessidade de 
ajuda) a escolha das fontes também variou nos mesmos quesitos: com a postura do professor, com a preferência do aluno e com a matéria em questão. Como se observou, o interesse pessoal na disciplina e a afinidade com as matérias estudadas foram feitas com mais celeridade, demandaram menos ajuda e necessidade de retorno; ao passo que motivaram pesquisas mais aprofundadas e a propensão à consulta e conjugação de mais de uma fonte.

Uma peculiaridade desta escola foi constatada ao observar a ausência da biblioteca escolar e do bibliotecário nas atividades estudantis. Viu-se que a biblioteca não é considerada canal de acesso às fontes de informação pelos alunos (pondera-se sobre a condição financeira da amostra, que usufrui de dispositivos digitais e opta pela posse dos livros). Descrevendo a situação da biblioteca, segundo o vice-diretor, o espaço estava sendo pouco e mal utilizado e suas potencialidades não estavam sendo devidamente exploradas, o que de certo modo, caracteriza uma biblioteca não integrada com a sala de aula. A direção da escola ponderou e reforçou o interesse em experimentar uma nova proposta de biblioteca com a decisão de fragmentar o acervo. Diante disso, ao pensar em relação à presença de um bibliotecário nesta escola específica, e como ele poderia contribuir com os estudantes, retomam-se os alicerces fundamentais sobre os quais se estrutura a proposta da escola: a autonomia do sujeito e o emprego da pesquisa escolar como ferramenta essencial de efetivação e consolidação do aprendizado. A estes fatores somam-se a colaboração entre os estudantes e a midiatização pelas novas tecnologias de informação e comunicação, outro fator encontrado na obra de Kuhlthau (2010): ensinar os alunos a usufruir dos dispositivos de forma produtiva na criação do conhecimento. 


\section{Conclusão}

Observou se que as teorias do aprendizado investigativo propiciam uma nova forma de pensar, aprender e ensinar; que envolve toda a estrutura da escola no sentido de instituir uma comunidade culturalmente colaborativa e interessada em interagir com a informação. Diante da 'sociedade da informação' muitas das pesquisas em Ciência da Informação têm sugerido que a competência informacional - aqui abordada como a perícia e competência para se prosperar na dinâmica dos múltiplos ambientes de informação - é a essência do que significa ser educado no século 21. Isso indica uma colaboração e parceria entre a biblioteca e a sala de aula; entre professores e bibliotecários, em benefício dos alunos. Os primeiros são os que passam mais tempo com os estudantes e enfrentam de forma mais próxima os desafios de promover uma aprendizagem efetiva e proveitosa através da educação formal que se sistematiza na escola. Contudo, a missão de ensinar não é restrita aos professores. Os bibliotecários também podem ser capacitados para preparar os alunos para a aprendizagem. É interessante que os professores, mais cientes das demandas na educação e do dia a dia dos alunos, possam interagir com o bibliotecário, para que este, dentre outras ações, possa sugerir novas formas de abordar o aluno e conduzir o aprendizado.

Uma vez que a escola pesquisada deseja implantar uma consciência coletiva que extrapole a materialidade da antiga biblioteca e consolide uma cultura de biblioteca (um ideal/uma mentalidade de biblioteca) identifica-se a emersão de um bibliotecário com perfil de educador/mediador para influenciar na aprendizagem e cooperar em uma consciência de que biblioteca não se restringe a livro, mas também às ferramentas de buscas automáticas, aos bancos de dados e demais aspectos relativos ao universo informacional. O foco se desloca da organização da informação para o doutrinamento do usuário e a mediação dos processos de busca de informação orientados para uma maior autonomia e segurança do sujeito.

O Inquiry Learning desponta portanto como um referencial, uma alternativa, para ajudar a contornar a complexidade do ensino contemporâneo. Professores informados de que os estudantes convivem com uma maciça oferta de informação e cada vez mais se voltam para a Internet ao fazer pesquisas para suas atribuições e bibliotecários, cientes do conteúdo programático e das competências que precisam ser trabalhadas pelos alunos, podem definir em conjunto como o aprendizado pode ocorrer; que tipo de pesquisa adotar, como definir os temas e a forma como serão abordados. Considera-se interessante experimentar o modelo de pesquisa orientada e observar a respostas dos alunos, bem como a relação professor-bibliotecário no 
processo, para então descrever e compartilhar, incrementando assim o crescimento na pesquisa em Ciência da Informação e na prática do bibliotecário.

\section{Referências}

ARAÚJO, C. A. Á.; BRAGA, R. M. O.; VIEIRA W. O. A contribuição de C. Kuhlthau para a Ciência da Informação no Brasil. Revista Digital de Biblioteconomia e Ciência da Informação, Campinas, v. 7, n. 2, p. 185-198, jan./jun. 2010. Disponível em: < http://www.sbu.unicamp.br/seer/ojs/index.php/rbci/article/view/439>. Acesso em: jun. 2016.

FIALHO, J. Experiência com estudantes do ensino médio através da pesquisa escolar orientada. Perspectivas em Ciência da Informação, Belo Horizonte, v. 18, n. 1, p. 15-25, mar. 2013.

KUHLTHAU, C. C. O papel da biblioteca escolar no processo de aprendizagem. In: VIANNA, M. M.; CAMPELLO, B.; MOURA, V. H. V. Biblioteca escolar: espaço de ação pedagógica. Belo Horizonte: EB/UFMG, 1999. p. 9-14.

Seeking meaning: a process approach to library and information services. 2. ed. Norwood: Ablex, 2004. 247 p.

Guided inquiry: school libraries in the 21 st century. School Libraries Worldwide, v. 16, n. 1, jan. 2010, p. 17-28. Disponível em: 〈http://twixar.me/mc0>. Acesso: jul. 2014.

.; MANIOTES, L. K.; CASPARI, A. K. Guided inquiry design: a framework for inquiry in your school. Santa Barbara: Libraries Unlimited, 2012. 188 p.

.; COLE, C. Third space as an information system and services intervention methodology for engaging the user's deepest levels of information need. ASIST 2012, oct. 28-31, 2012. Disponível em:

<https://www.asis.org/asist2012/proceedings/Submissions/74.pdf>. Acesso em: 19 mar. 2015.

LANZI, L. A. C; VIDOTTI, S. G. A. B.; FERNEDA, E. A biblioteca escolar e a geração nativos digitais: construindo novas relações. São Paulo: Cultura Acadêmica, 2013. 195 p.

MILLER, W.; PELLEN, R. M. (Org.). Libraries and Google. Binghamton: Haworth Information, 2005. $240 \mathrm{p}$.

OLIVEIRA, I. R. O processo de aprendizagem pela busca e uso de informações: a orientação da pesquisa escolar na perspectiva do professor. 2013. 95 f. Dissertação (Mestrado em Ciência da Informação) - Universidade Federal de Minas Gerais, Escola de Ciência da Informação, Belo Horizonte, 2013.

OLIVEIRA, J. B. A.; SCHWARTZMAN, S. A escola vista por dentro. Belo Horizonte: Alfa Educativa, 2002. 144 p.

PALFREY, J. G.; GASSER, U. Born digital: understanding the first generation of digital natives. New York: Basic Books, 2008. 375 p. 
Maria L. Amorim Antunes e Adriana Bogliolo Sirihal Duarte

PRENSKY, M. Digital natives, digital immigrants. On the Horizon, v. 9, n. 5, out. 2001.

SIBILIA, P. Redes ou paredes: a escola em tempos de dispersão. Rio de Janeiro:

Contraponto, 2012. 222 p.

TAPSCOTT, D. Grown up digital: how the net generation is changing your world. New York: McGraw Hill, 2009. 385 p.

WILLIAMS, G. Unclear on the context: refocusing on information literacy's evaluative component in the age of google. LPP Special Issue on Libraries and Google; Library Philosophy and Practice, jun. 2007. 